\title{
Chronic thromboembolic pulmonary hypertension: Medical treatment
}

\author{
Savas Ozsul and Halit Cinarka ${ }^{2}$ \\ ${ }^{1}$ Department of Pulmonary Medicine, Karadeniz Technical University School of Medicine, Trabzon; and ${ }^{2}$ Department of Pulmonary \\ Medicine, Recep Tayyip Erdoğan University School of Medicine, Rize, Turkey
}

\begin{abstract}
Chronic thromboembolic pulmonary hypertension (CTEPH) is responsible for significant levels of morbidity and mortality. The estimated cumulative incidence of CTEPH is $2-4 \%$ among patients presenting with acute pulmonary thromboembolism. Currently, at the time of CTEPH diagnosis, $37.9 \%$ of the patients in an international registry were receiving at least one pulmonary arterial hypertension (PAH)-targeted therapy. Advanced medical therapy is considered in patients with inoperable disease, as a bridge to pulmonary endarterectomy or in those with persistent or recurrent pulmonary hypertension. PAH-specific medical therapies include endothelin receptor antagonists, phosphodiesterase inhibitors, and prostacyclin analogues. The present article will focus on recent developments in the pharmacological treatment of CTEPH.
\end{abstract}

Key Words: chronic thromboembolism, medical treatment, pulmonary hypertension

Chronic thromboembolic pulmonary hypertension (CTEPH) is the presence of mean pulmonary artery pressure (mPAP) $\geq 25 \mathrm{mmHg}$ following an episode of pulmonary thromboembolism (PTE). CTEPH is a rare complication of PTE; however, it is associated with significant rates of mortality and morbidity. The three-year mortality was reported as $90 \%$ in the patients with PAP > $50 \mathrm{mmHg}^{[1]}$ CTEPH is included in Group IV according to the 2008 Dana Point Classification. ${ }^{[2]}$ The CTEPH incidence after the first PTE episode varies between $2 \%$ and $4 \%{ }^{[3,4]}$ The incidence of CTEPH was $4.6 \%$ in our study, which followed 325 patients for a mean duration of 16.3 months at our center. ${ }^{[5]}$ Interestingly, the majority of the subjects diagnosed with CTEPH did not have a previous PTE diagnosis. ${ }^{[6,7]}$ Currently, available data demonstrate the frequency of CTEPH in the symptomatic patients and suggest that the rate is actually higher when considering the asymptomatic and unscreened patients.

The present review discusses the pharmacological treatment of CTEPH in light of the current literature. The review will particularly focus on the outcomes obtained in CTEPH with specific medical treatments (prostacyclin analogues, endothelin receptor antagonists, and phosphodiesterase-5 inhibitors) used in idiopathic pulmonary arterial hypertension (IPAH).

\section{DIAGNOSIS}

CTEPH should be considered in patients with an $\mathrm{mPAP} \geq 25 \mathrm{mmHg}$ in echocardiography and unexplained dyspnea and/or previous PTE history (in the preceding six months or more). It should be kept in mind that the risk of developing CTEPH is particularly high in patients with certain risk factors (e.g., recurrent PTE, splenectomy, lupus anticoagulant, or antiphospholipid antibodies) ${ }^{[8]}$ Computed tomography pulmonary angiography or ventilation perfusion scan should be performed for definitive diagnosis in these patients. Subsequently, right heart catheterization should be performed in order to confirm the diagnosis of pulmonary hypertension $(\mathrm{PH})$ and to demonstrate the hemodynamic state. The treatment decision should be planned with a multidisciplinary approach (including chest diseases, cardiology, cardiovascular surgery, and radiology). ${ }^{[9,10]}$

\begin{tabular}{|l|l|}
\hline \multicolumn{3}{|c|}{ Access this article online } \\
\hline Quick Response Code: & Website: www.pulmonarycirculation.org \\
\hline & DOI: 10.4103/2045-8932.114761 \\
\cline { 2 - 2 } & $\begin{array}{l}\text { How to cite this article: Ozsu S, Cinarka } \\
\text { H. Chronic thromboembolic pulmonary } \\
\text { hypertension: Medical treatment. Pulm Circ } \\
\text { 2013;3:341-4. }\end{array}$ \\
\end{tabular}




\section{TREATMENT APPROACH}

The primary treatment is pulmonary thromboendarterectomy (PEA) in the patients diagnosed with CTEPH. PEA indications are 1) New York Heart Association (NYHA) Functional Class III or IV; 2) pulmonary vascular resistance (PVR) higher than 300 dyn.s $/ \mathrm{cm}^{5}$ prior to surgery; 3) surgically accessible thrombi in main, lobar, or segmental pulmonary arteries; and 4) absence of other concomitant severe conditions. ${ }^{[2]}$ However, approximately $20-40 \%$ of CTEPH patients are considered inoperable. ${ }^{[11,12]}$ In patients with an $\mathrm{mPAP}<40 \mathrm{mmHg}$ and an $\mathrm{mPAP}>50 \mathrm{mmHg}$ in whom PEA is not performed, five-year survival was reported as $30 \%$ and $10 \%$, respectively. ${ }^{[13,14]}$

The major vessel obstruction and remodeling combined with small vessel arteriopathy in CTEPH were shown to be histologically indistinguishable from the classical arteriopathy observed in pulmonary arterial hypertension (PAH). Therefore, PAH-specific treatment may be used in patients with CTEPH due to the morphological changes resembling IPAH. ${ }^{[15]}$

Currently, $37.9 \%$ of CTEPH patients are reported as receiving $\mathrm{PAH}$-specific treatments. ${ }^{[16]}$ Medical treatment is recommended for four patient groups in CTEPH: (1) Patients ineligible for endarterectomy due to distal thrombus (segmental, subsegmental); (2) prior to PEA; (3) persistent PH following PEA; and (4) patients in whom PEA in contraindicated due to concomitant comorbid conditions (severe pulmonary parenchymal disease, morbid obesity, hepatic or renal dysfunction, diabetes mellitus, and coronary artery disease). ${ }^{[15]}$

Additionally, the patients in whom a decrease less than $50 \%$ is expected in pulmonary vascular resistance following PEA and the patients with PVR $>1,200$ dyn.s $/ \mathrm{cm}^{5}$ are also considered ineligible for PEA. ${ }^{[12]}$ A study reported mortality rates as $4 \%, 10 \%$, and $20 \%$ in the patients with PVR $<900$ dyn.s $/ \mathrm{cm}^{5}$, PVR $=900-1200$ dyn.s $/ \mathrm{cm}^{5}$, and PVR $>1,200$ dyn.s $/ \mathrm{cm}^{5}$, respectively. ${ }^{[10]}$

Standard medical treatment of CTEPH consists of diuretics, oxygen therapy, and life-long anticoagulant therapy. ${ }^{[17]}$ The target of anticoagulant therapy should be an international normalized ratio of 2-3. Anticoagulant therapy prevents in situ pulmonary artery thrombosis and recurrent thromboembolism. ${ }^{[18]}$ Long-term anticoagulant therapy was shown to reduce the risk of recurrent thromboembolism, particularly in patients with idiopathic or unprovoked pulmonary embolism. ${ }^{[19,20]}$ In a small study including 10 patients with an mPAP below $30 \mathrm{mmHg}$ who were receiving oral anticoagulant therapy, the functional capacity (FC) was shown to reduce from II to I over three years. ${ }^{[21]}$

\section{PAH-SPECIFIC TREATMENTS}

\section{Treatment of inoperable patients}

In the BENEFIT (Bosentan Effects in iNopErable Forms of CTEPH) study comparing a total of 157 patients with CTEPH (80 patients on placebo and 77 patients on bosentan) for 16 weeks, PVR and cardiac index (CI) were improved, while no difference was found in 6-Minute Walk Distance test (6MWD) and FC. ${ }^{[22]}$ In a study evaluating 104 patients (76 patients with FC III) by using high doses $(3 \times 50 \mathrm{mg})$ sildenafil, notable improvement was detected in PVR, CI, 6MWD, and FC. The increase of $51 \mathrm{~m}$ in $6 \mathrm{MWD}$ over three months was observed to be maintained for 12 months. ${ }^{[23]}$

In a randomized, double-blind, placebo-controlled study including 19 inoperable patients with CTEPH, using sildenafil, an increase of 36 (8-64) $\mathrm{m}$ was found in 6MWD over 12 months. Again, a 19\% decrease was determined in NT-proBNP levels compared to baseline. ${ }^{[2]}$

Olchewski et al. ${ }^{[25]}$ conducted a placebo-controlled study with iloprost in a total of 203 patients (57 inoperable CTEPH patients). This 12-week study, also known as the Aerosolized Iloprost Randomized study, also demonstrated significant improvement in PVR, 6MWD, and cardiac output. One of the important results of this study was the two-fold increase observed in 6MWD in the IPAH group compared to patients with CTEPH.

In a retrospective study on epoprostenol conducted with 27 inoperable CTEPH patients (FC III $[n=20]$ and FC IV $[n=7]$ ), mPAP (pretreatment: $56 \mathrm{mmHg}$, post-treatment: $51 \mathrm{mmHg}$ ) and PVR (pretreatment: $29.3 \mathrm{U} / \mathrm{m}^{2}$, posttreatment: $23.0 \mathrm{U} / \mathrm{m}^{2}$ ) were shown to decrease, while a significant improvement (an increase of $66 \mathrm{~m}$ ) was demonstrated in 6MWD over three months. The one-year, two-year, and three-year survival rates were found as $73 \%$, $59 \%$, and $41 \%$, respectively. ${ }^{[26]}$

A single-center, uncontrolled observational study was conducted with subcutaneous treprostinil in 28 inoperable patients with severe CTEPH. Catheterization was performed over $19 \pm 6.3$ months for the 19 patients under follow-up. Treprostinil provided a notable improvement in PVR. The five-year survival was $53 \%$ in the group receiving treprostinil versus $16 \%$ in the untreated group. ${ }^{[27]}$

\section{Pre-PEA treatment}

The majority of the patients' candidate for preoperative PEA is hemodynamically instable in the perioperative period, therefore causing an increased surgical risk. Patients in NYHA Class IV, those with an mPAP $>50 \mathrm{mmHg}$, patients with a $\mathrm{CI}<2.0 \mathrm{~L} / \mathrm{min} / \mathrm{m}^{2}$, and those with PVR > 1,000 dyn.s $/ \mathrm{cm}^{5}$ are defined as patients at 
high preoperative risk. In such patients with CTEPH, medical treatment improves preoperative pulmonary hemodynamics and increases surgical success. ${ }^{[15]}$

In a study with 33 patients (21 patients with PVR < 1,200), 12 patients received intravenous prostacyclin, and pre-PEA medical treatment was administered to 21 patients. This study showed a significant decrease in PVR (pretreatment: $1.510 \pm 53$, post-treatment: 1,088 \pm 58 dyn.s $/ \mathrm{cm}^{5} ; P<0.001$ ) and plasma BNP levels (pretreatment: $547 \pm 112$, post-treatment; $188 \pm 30 \mathrm{pg} / \mathrm{mL} ; P<0.01$ ) in the pre-PEA prostacyclin. Group 1 patients $(8.3 \%)$ in the prostacyclin group died due to severe CTEPH during the perioperative period. The time from medical treatment to PEA was reported as $46 \pm 12$ days, and the mean prostacyclin dose was reported as $6 \pm 1 \mathrm{ng} / \mathrm{kg} / \mathrm{min}$ in this study. ${ }^{[28]}$

In a retrospective study, Jensen et al. ${ }^{[29]}$ demonstrated that preoperative treatment provided minimal improvement in hemodynamics and caused delays regarding surgery. Therefore, administration of preoperative medical treatment should not delay the surgical process of the patient. Another important issue is the fact that the duration of medical treatment to be administered prior to surgery is not clear in these patients. ${ }^{[15]}$

\section{Post-PEA treatment}

Persistent PH was demonstrated in approximately 10-15\% of post-PEA patients. ${ }^{[30]}$ In particular, distal vasculopathy with morphological changes similar to IPAH, also known as "Class IV CTEPH," was shown in CTEPH patients developing persistent $\mathrm{PH}$ in the post-PEA period. ${ }^{[10]}$ Therefore, specific treatments are suggested to be effective in this patient group. There are limited data in literature regarding the use of medical treatment in patients with postsurgical persistent PH. A total of 469 patients were included in a multicenter, prospective, observational study where 236 patients had PEA and 148 patients received medical treatment as they were ineligible for surgery due to distal thrombus. In this study, persistent $\mathrm{PH}$ was defined as $\mathrm{mPAP} \geq 25 \mathrm{mmHg}$ and PVR $>240$ dyn.s/ $\mathrm{cm}^{5}$. Persistent PH developed in 70 (35\%) patients during the postoperative period. Medical treatment was added for patients with PAB $\geq 30 \mathrm{mmHg}$. At the end of two years, $18 \%$ of the patients who underwent surgery had received medical treatment. Survival at one to three years in the surgical group was found as $88-76 \%$, respectively; and as $82-70 \%$ in the medical group, respectively $(P=0.023)$. However, the functional improvement achieved in three months in the medical group was not maintained in Year $2 .^{[31]}$

Kramm et al. ${ }^{[32]}$ conducted another placebo-controlled study with 22 patients and demonstrated substantial improvement in hemodynamic parameters (mPAP, PVR, and decreased Right Ventricle afterload and increased CI) of the patients who received iloprost following PEA.

Riociguat, an oral, soluble guanylate cyclase stimulator affecting the nitric oxide receptor has been studied in patients with CTEPH. ${ }^{[33]}$ Inoperable patients with CTEPH (42 patients) and PAH (33 patients) with FC II-III were included and followed for 12 weeks in a multicenter Phase II study. Patients with CTEPH showed an increase of $55.0 \mathrm{~m}$ while patients with $\mathrm{PAH}$ showed an increase of $57.0 \mathrm{~m}$ in $6 \mathrm{MWD}$, showing a statistically significant difference compared to baseline. In this study, $56 \%$ of the patients experienced adverse events and these side effects resulted in discontinuation of the drug in $4 \%$ of the patients. The most common side effects were reported as dyspepsia, headache, and hypotension. ${ }^{[34]}$

\section{CONCLUSION}

Currently, studies on the use of PAH-specific treatments in patients with CTEPH are retrospective and nonrandomized studies conducted in heterogeneous patient groups. There is no specific medical treatment currently approved for CTEPH. PEA remains as the main and curative treatment in CTEPH. However, PAH-specific treatments should be considered in patients ineligible for PEA.

\section{REFERENCES}

1. Dalen JE, Alpert JS. Natural history of pulmonary embolism. Prog Cardiovasc Dis 1975;17:259-70.

2. Torbicki A, Perrier A, Konstantinides S, Agnelli G, Galiè N, Pruszczyk P, et al. Guidelines on the diagnosis and management of acute pulmonary embolism: The Task Force for the Diagnosis and Management of Acute Pulmonary Embolism of the European Society of Cardiology (ESC). Eur Heart J 2008;29:2276-315.

3. Pengo V, Lensing AW, Prins MH, Marchiori A, Davidson BL, Tiozzo F, et al. Incidence of chronic thromboembolic pulmonary hypertension after pulmonary embolism. N Engl J Med 2004;350:2257-64.

4. Becattini C, Agnelli G, Pesavento R, Silingardi M, Poggio R, Taliani MR, et al. Incidence of chronic thromboembolic pulmonary hypertension after a first episode of pulmonary embolism. Chest 2006;130:172-5.

5. Korkmaz A, Ozlu T, Ozsu S, Kazaz Z, Bulbul Y. Long-term outcomes in acute pulmonary thromboembolism: The incidence of chronic thromboembolic pulmonary hypertension and associated risk factors. Clin Appl Thromb Hemost 2012;18:281-8.

6. Lang IM. Chronic thromboembolic pulmonary hypertension - Not so rare after all. N Engl J Med 2004;350:2236-8.

7. Colorio CC, Martinuzzo ME, Forastiero RR, Pombo G, Adamczuk Y, Carreras LO. Thrombophilic factors in chronic thromboembolic pulmonary hypertension. Blood Coagul Fibrinolysis 2001;12:427-32.

8. Piazza G, Goldhaber SZ. Chronic thromboembolic pulmonary hypertension. N Engl J Med 2011;364:351-60.

9. Hoeper MM, Mayer E, Simonneau G, Rubin LJ. Chronic thromboembolic pulmonary hypertension. Circulation 2006;113:2011-20.

10. Dartevelle P, Fadel E, Mussot S, Chapelier A, Hervé P, de Perrot M, et al. Chronic thromboembolic pulmonary hypertension. Eur Respir J 2004;23:637-48.

11. Mayer E, Jenkins D, Lindner J, D’ Armini A, Kloek J, Meyns B, et al. Surgical management and outcome of patients with chronic thromboembolic pulmonary hypertension: Results from an international prospective registry. J Thorac Cardiovasc Surg 2011;141:702-10. 
12. Mayer E. Surgical and post-operative treatment of chronic thromboembolic pulmonary hypertension. Eur Respir Rev 2010;19:64-7.

13. Moser KM, Auger WR, Fedullo PF. Chronic major-vessel thromboembolic pulmonary hypertension. Circulation 1990;81:1735-43.

14. Kunieda T, Nakanishi N, Satoh T, Kyotani S, Okano Y, Nagaya N. Prognoses of primary pulmonary hypertension and chronic major vessel thromboembolic pulmonary hypertension determined from cumulative survival curves. Intern Med 1999;38:543-6.

15. Bresser P, Pepke-Zaba J, Jaïs X, Humbert M, Hoeper MM. Medical therapies for chronic thromboembolic pulmonary hypertension: an evolving treatment paradigm. Proc Am Thorac Soc 2006;3:594-600.

16. Pepke-Zaba J, Delcroix M, Lang I, Mayer E, Jansa P, Ambroz D, et al. Chronic thromboembolic pulmonary hypertension (CTEPH): Results from an international prospective registry. Circulation 2011;124:1973-81.

17. Gölbaşı Z. Chronic thromboembolic pulmonary hypertension: diagnosis, medical therapy and monitoring. Anadolu Kardiyol Derg 2010;10;56-60.

18. Jenkins D, Mayer E, Screaton N, Madani M. State-of-the-art chronic thromboembolic pulmonary hypertension diagnosis and management. Eur Respir Rev 2012;21:32-9.

19. Ridker PM, Goldhaber SZ, Danielson E, Rosenberg Y, Eby CS, Deitcher SR, et al. Long-term, low-intensity warfarin therapy for the prevention of recurrent venous thromboembolism. N Engl J Med 2003;348:1425-34.

20. Kearon C, Ginsberg JS, Kovacs MJ, Anderson DR, Wells P, Julian JA, et al. Comparison of low-intensity warfarin therapy with conventionalintensity warfarin therapy for long-term prevention of recurrent venous thromboembolism. N Engl J Med 2003;349:631-9.

21. Romaszkiewicz R, Lewczuk J, Piszko P, Lenartowska L, Jagas J, Konieczny A, et al. Clinical course of unoperated mild chronic thromboembolic pulmonary hypertension. Kardiol Pol 2011;69:438-43.

22. Jais X, D'Armini A, Jansa P, Torbicki A, Delcroix M, Ghofrani HA, et al. Bosentan for treatment of inoperable chronic thromboembolic pulmonary hypertension: BENEFiT (Bosentan Effects in iNopErable Forms of chronIc Thromboembolic pulmonary hypertension), a randomized, placebocontrolled trial. J Am Coll Cardiol 2008;52:2127-34.

23. Reichenberger F, Voswinckel R, Enke B, Rutsch M, El Fechtali E, Schmehl T, et al. Long-term treatment with sildenafil in chronic thromboembolic pulmonary hypertension. Eur Respir J 2007;30:922-7.

24. Suntharalingam J, Treacy CM, Doughty NJ, Goldsmith K, Soon E,
Toshner MR, et al. Long-term use of sildenafil in inoperable chronic thromboembolic pulmonary hypertension. Chest 2008;134:229-36.

25. Olchewski H, Simonneau G, Galie N, Higenbottam T, Naeije R, Rubin LJ, et al. Inhaled iloprost for severe pulmonary hypertension. N Engl J Med 2002;347:322-9.

26. Cabrol S, Souza R, Jais X, Fadel E, Ali RH, Humbert M, et al. Intravenous epoprostenol in inoperable chronic thromboembolic pulmonary hypertension. J Heart Lung Transplant 2007;26:357-62.

27. Skoro-Sajer N, Bonderman D, Wiesbauer F, Harja E, Jakowitsch J, KlepetkoW, et al. Treprostinil for severe inoperable chronic thromboembolic pulmonary hypertension. J Thromb Haemost 2007;5:483-9.

28. Nagaya N, Sasaki N, Ando M, Ogino H, Sakamaki F, Kyotani S, et al. Prostacyclin therapy before pulmonary thromboendarterectomy in patients with chronic thromboembolic pulmonary hypertension. Chest 2003;123:338-43.

29. Jensen KW, Kerr KM, Fedullo PF, Kim NH, Test VJ, Ben-Yehuda O, et al. Pulmonary hypertensive medical therapy in chronic thromboembolic pulmonary hypertension before pulmonary thromboendarterectomy. Circulation 2009;120:1248-54.

30. Auger WR, Kerr KM, Kim NH, Ben-Yehuda O, Knowlton KU, FedulloPF. Chronic thromboembolic pulmonary hypertension. Cardiol Clin 2004;22:453-66.

31. Condliffe R, Kiely DG, Gibbs JS, Corris PA, Peacock AJ, Jenkins DP, et al. Improved outcomes in medically and surgically treated chronic thromboembolic pulmonary hypertension. Am J Respir Crit Care Med 2008;177:1122-7.

32. Kramm T, Eberle B, Guth S, Mayer E. Inhaled iloprost to control residual pulmonary hypertension following pulmonary endarterectomy. Eur J Cardiothorac Surg 2005;28:882-8.

33. Kim NH. Riociguat: An upcoming therapy in chronic thromboembolic pulmonary hypertension? Eur Respir Rev 2010;19:68-71.

34. Ghofrani HA, Hoeper MM, Halank M, Meyer FJ, Staehler G, Behr J, et al. Riociguat for chronic thromboembolic pulmonary hypertension and pulmonary arterial hypertension: A phase II study. Eur Respir J 2010;36:792-9.

Source of Support: Nill, Conflict of Interest: None declared. 